\title{
Correction to: Migrant farmworker injury: temporality, statistical representation, eventfulness
}

\author{
Seth M. Holmes ${ }^{1,2,3}$
}

Published online: 29 July 2019

(c) Springer Nature B.V. 2019

\section{Correction to: Agriculture and Human Values https://doi.org/10.1007/s10460-019-09965-8}

The original version of this article was revised due to missing institute information in the "Context: methods and positionality" section. Where it says "there is IRB approval from $\mathrm{X}$ University", it should specify "there is IRB approval from the University of California Berkeley".

Publisher's Note Springer Nature remains neutral with regard to jurisdictional claims in published maps and institutional affiliations.

The original article can be found online at https://doi.org/10.1007/ s10460-019-09965-8.

Seth M. Holmes

sethmholmes@berkeley.edu

1 Division of Society and Environment and Joint Program in Medical Anthropology, UC Berkeley, Berkeley, USA

2 Joint Program in Medical Anthropology, UC San Francisco, San Francisco, USA

3 Alameda County Medical Center, Oakland, USA 